\title{
The hidden costs of flexible fertility
}

\section{Urgent public debate is needed over a European proposal to regulate environmental levels of the active ingredient in birth-control pills, say Richard Owen and Susan Jobling.}

$\mathrm{M}$ ore than 100 million women worldwide use contraceptive pills ${ }^{1}$. The active ingredient in most formulations is ethinyl estradiol (EE2), which is excreted from the body along with other, naturally occurring, oestrogens, passing through waste-water works into rivers, estuaries and lakes.

Decades of research have shown that EE2 and other oestrogens cause widespread damage in the aquatic environment by disrupting endocrine systems in wildlife. This includes a condition called intersex: the irreversible development of eggs in the testes of male fish, which reduces their reproductive success ${ }^{1}$. When researchers introduced EE2 into a Canadian lake in 2001 at the vanishingly low level of 5 parts per trillion, the population of one fish species collapsed ${ }^{2}$. The potency of EE2 as an endocrine disrupter makes it a serious threat to wildlife and fisheries.

Governments across the globe have been painfully slow in their response to this issue. In 2004, some 30 years after the first observations of intersex in fish in British rivers, the UK Environment Agency agreed that there was a strong case for risk management ${ }^{3}$. But it was only in January this year that the European Commission announced its intention to regulate EE2 under the Water Framework Directive (see go.nature.com/8fm $3 \mathrm{dz}$ ). European countries would be required by 2021 to limit EE2 in water bodies to an annual average of no more than 0.035 parts per trillion.

This regulation will set a global precedent for regulating pharmaceuticals in the environment. It also presents society with a difficult dilemma, of which the public remains mostly unaware.

\section{THE CONTROL DILEMMA}

The pharmaceutical and water industries, and many governments, are strongly opposed to this proposed regulation. One reason is the high cost of compliance. The maximum permissible concentration of EE2 would be very low, reflecting the level at which damage occurs to aquatic organisms. The only currently effective option for removing EE2 from waste water to allow compliance involves adsorption on to

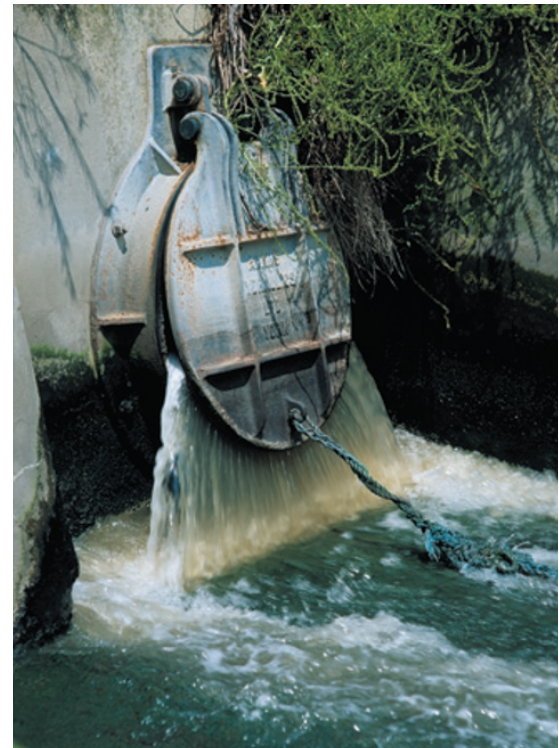

Treating waste water to remove oestrogens will cost European countries billions of euros.

granular activated carbon. For a UK town of around 250,000 people, such a system would cost more than $€ 8$ million (US $\$ 10.3$ million) to install and around $€ 800,000$ a year to operate ${ }^{1}$. For the 1,400 waste-water works that would need upgrading in England and Wales alone, this would amount to more than $€ 30$ billion in total.

These costs - for EE2 and possibly other pharmaceuticals in the future - will be borne by the public through higher water prices. Are we willing to pay, or would we rather settle for environmental harm as collateral damage associated with flexible fertility? The answer to this dilemma is not obvious, either in Europe or worldwide.

Difficult decisions that affect us all should include us all. But there has been little open debate as to how environmental pharmaceuticals such as EE2 should be regulated. A workshop attended by representatives of governments, industry and environmental groups was convened by the European Parliament on 24 April to discuss EE2 and other 'priority substances' that are slated for regulation. But by not including the public, the European Commission is falling short of its own recommendation that "all interested parties should be involved to the fullest extent possible" in assessing risk-management options ${ }^{4}$. The UK Royal Commission on Environmental Pollution has also stressed that such decisions must take into account peoples' values, and that "it is no longer acceptable for decisions to be negotiated privately between the regulator and polluter"

The need to protect our environment from the harmful effects of EE2 is clear, but understanding of our willingness as a society to pay for that protection is not. Nor is it obvious where responsibilities lie, including whether pharmaceutical companies have a moral duty of care for all their products, which could be better designed so that they are safe for the environment.

On 6 November 2012, a European Parliament legislative committee will vote on whether EE2 should be included in the priority substances list for regulation, and whether the legislation should progress to a first reading in the European Parliament next January. These decisions must be democratic, equitable and legitimate. The public must be informed about the scientific evidence, and the costs of action or inaction openly debated. A decision on whether or not to regulate EE2 must include the people it will affect, whatever the outcome.

Richard Owen is chair in responsible innovation at the University of Exeter Business School, Exeter EX4 4PU, UK. Susan Jobling is chair in environmental toxicology and head of the Institute for the Environment at Brunel University, Uxbridge, Middlesex UB8 3PH, UK. e-mail:r.j.owen@exeter.ac.uk

1. Jobling, S. \& Owen, R. Ethinyl oestradiol: bitter pill for the precautionary principle in: Late Lessons from Early Warnings: Science, Precaution, Innovation (European Environment Agency, in the press).

2. Kidd, K. A. et al. Proc. Natl Acad. Sci. USA 104, 8897-8901 (2007).

3. Gross-Sorokin, M. Y., Roast, S. D. \& Brighty, G. C. Environ. Health Perspect. 114 (S1), 147-151 (2006).

4. European Commission. Communication from the Commission on the Precautionary Principle COM (2000)1 (2000)

5. Royal Commission on Environmental Pollution Report no. 21: Setting Environmental Standards (RCEP, 1998). 